\title{
TEACHING COMPLICATED CONCEPTUAL KNOWLEDGE WITH SIMULATION VIDEOS IN FOUNDATIONAL ELECTRICAL ENGINEERING COURSES
}

\author{
Baiyun Chen (D), Lei Wei (iD, Huihui Li (D) \\ University of Central Florida (United States) \\ baiyun.chen@,ucf.edu, Lei.Wei@ucf.edu, lihuihui900@gmail.com
}

Received June 2015

Accepted June 2016

\section{Abstract}

Building a solid foundation of conceptual knowledge is critical for students in electrical engineering. This mixed-method case study explores the use of simulation videos to illustrate complicated conceptual knowledge in foundational communications and signal processing courses. Students found these videos to be very useful for establishing concepts, understanding course content and increasing general knowledge in electrical engineering. We hope that the findings can help inform best practices for producing engaging and effective instructional videos for engineering courses; inspire instructors of electrical engineering to transform their teaching practice; and eventually benefit students by building a solid conceptual understanding that fosters the development of further engineering competencies.

Keywords - Conceptual knowledge, Electrical engineering, Simulation, Telecommunication, Instructional video, Undergraduate education. 


\section{Introduction}

Engineers rely heavily on conceptual knowledge to understand the interrelationships of basic engineering concepts used during their professional practice. While working, they need to solve problems and make judgments quickly and efficiently without having to refer to their textbooks for complex models or physical prototypes. This mode of operation is called engineering judgment or heuristic thinking (Streveler, Litzinger, Miller \& Steif, 2008). For example, electrical engineers need to quickly and accurately diagnose problems from digital transmission signals of an eye diagram (Lauterbach, 1997), a common indicator of the quality of signals in high-speed digital transmissions on an oscilloscope, just like medical doctors need to quickly figure out potential heart problems from an electrocardiogram (ECG).

Therefore, building a solid foundation of conceptual knowledge is a critical element in an electrical engineering curriculum. The conceptual knowledge foundation consists of two major components: the fundamental physical principles and the analytical procedures (Kapli, 2010). Fundamental physical principles involve understanding how a system operates and why. Analytical procedures are the mathematical equations that are essentially symbolic representations of the physical principles. An incomplete conceptual understanding hinders the development of central engineering competencies such as problem-solving and decision-making.

While conceptual knowledge is critical in the engineering curriculum, acquiring accurate understanding of these abstract and complicated concepts has been found to present substantial challenges to students. It is especially challenging in the field of electrical engineering since the concepts and procedures are complex and not directly observable. As learning scientists suggested, emergent processes that are not directly observable are the most difficult concepts to learn (Chi, 2005). For example, students can quickly learn how to convert $x(t)$ to $x(-t)$, or to $x(2 t)$ or to $x(t-3)$, but they have great difficulty in converting $x(t)$ to $x(-2 t-3)$. Students also experience difficulties in developing concepts about signal waveforms and understanding operations such as correlations and signal matching.

Researchers and educators have been researching teaching methods to help students foster a better understanding of complex conceptual knowledge. The cognitive theory of multimedia learning (Mayer, 2002) has suggested that students could learn more deeply using multimedia explanation, rather than mere verbal or textual explanation. Instructional videos have the ability to convey meanings through both auditory and visual channels, creating a multisensory learning environment. In engineering research, Streveler et al. (2008) also suggest that well-designed 
curricular materials coupled with computer simulation technologies could lead to substantial learning gains in conceptual knowledge acquisition. Therefore, simulation videos could be especially beneficial for students in engineering disciplines (Marques, Quintela, Restivo \& Trigo, 2013). Yet much remains unknown about what makes engaging and effective simulation videos (Hibbert, 2014; Guo, Kim \& Rubin, 2014). What characteristics of simulation videos influence students' learning? What characteristics engage students in learning? These are important questions to consider as instructors and course designers strategize the best ways to allocate design and production resources.

\section{The context of the study}

To investigate best instructional practices for using videos in engineering curriculum, we conducted a mixed-method case study to evaluate the use of short simulation videos in a foundational electrical engineering course.

\subsection{Course description}

Analog and Digital Communication Fundamentals (EEL3552C) is an undergraduate-level course required for third-year students in the Bachelor of Science degree in electrical engineering at the University of Central Florida. It is a 4 credit hour class that runs over a 16 -week semester in the spring, summer and fall semesters. The enrollment is approximately 65-75 students every semester. This class covers fundamental theories and design principles behind telecommunication systems. In telecommunications, machines talk in mathematical languages, i.e., signal wave forms. One of the key learning outcomes of this class is for students to understand signal waveform representations and operations. Since underlining signal waveforms are not readily observable and very different from human communications, students have had special challenges grasping these abstract concepts.

The class has been delivered conventionally through face-to-face lectures and paper-based examinations. In class, the instructor traditionally drew various signal waveforms on paper or printed still images for demonstration. However, the pen-and-paper method only presents snapshots of complex operations but does not accurately reflect various transformations of signal waveforms. In addition, the demonstration happened only in a short period of time in face-to-face lectures. If students did not understand or were absent-minded at the moment, they 
could miss these concepts completely and would struggle with further analytical procedures. As a result, more than half of the students in EEL3552C were struggling to interpret these waveforms in precise mathematical formula, and could not further develop skills to identify or solve related problems. Based on conversations with other instructors, the same issue happened in other electrical engineering classes and in other universities or institutions.

In 2012, the instructor of EEL3552C participated in a professional development program for designing and teaching courses with online technologies (IDL6543). During the program, he had the opportunity to reflect on his teaching strategies and course delivery. As a result, he integrated Canvas, the learning management system (LMS) to supplement his face-to-face teaching. He posted the course materials in a modular format inside the LMS and created a series of simulation videos to reinforce difficult concepts.

\subsection{Simulation video production}

Each video was produced using hundreds of simulation images generated by Matlab. Matlab is a basic but efficient mathematical tool for programming and simulation that is widely used in the engineering industry for research and development. Unlike other programming software, the programming language in Matlab is simple and the syntax is easy to remember. Equipped with thousands of internal functions, Matlab is convenient for mathematics calculation and figure plotting.

After the instructor selected the topics and drafted the outlines of these videos, a teaching assistant defined the variables, input formulae and generated single image frames using Matlab. Figures 1 to 5 illustrate the production process of mixing three signals, in which the second signal changes in amplitude and the third one changes in frequency. We first defined the formula (Figure 1) for the first sinusoid signal as $\mathrm{y}_{1}=\sin \left(2 \pi \mathrm{t}\right.$ ) (Figure 2). Here $\mathrm{y}_{1}$ is fixed and has no variable during the mixture. The second sinusoid signal is $\mathrm{y}_{2}=A \sin (2 \pi \mathrm{t})$ (Figure 3$)$, where $\mathrm{A}$ represents amplitude, changing from $-3 \mathrm{~V}$ to $2 \mathrm{~V}$. The third sinusoid signal is $\mathrm{y}_{3}=\sin (2 \pi \omega \mathrm{t})$ (Figure 4), where $\varpi$ is radians per second changing from $0.5 \mathrm{rad} / \mathrm{s}$ to $2 \mathrm{rad} / \mathrm{s}$. The summation of the three signals is $\mathrm{y}_{4}=\mathrm{y}_{1}+\mathrm{y}_{2}+\mathrm{y}_{3}$ (Figure 5). 


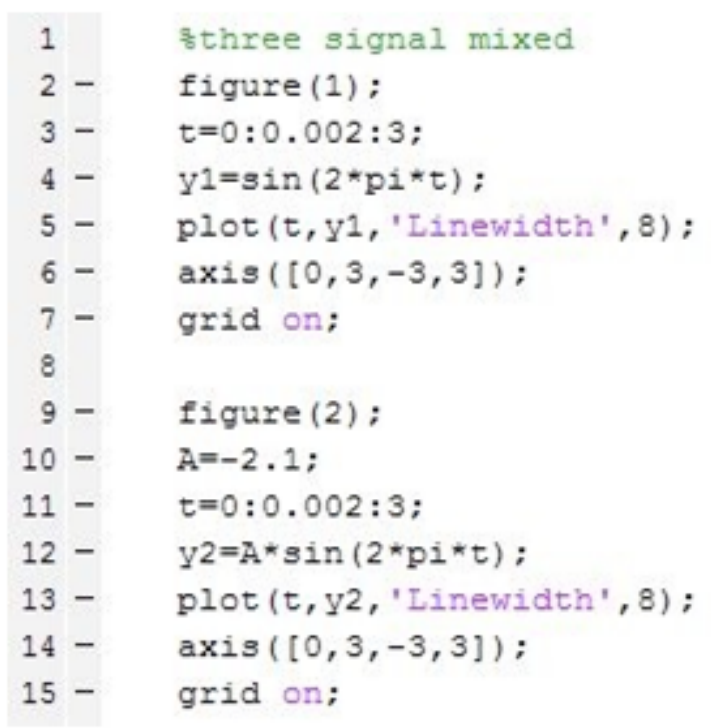

Figure 1. Define formula in Matlab

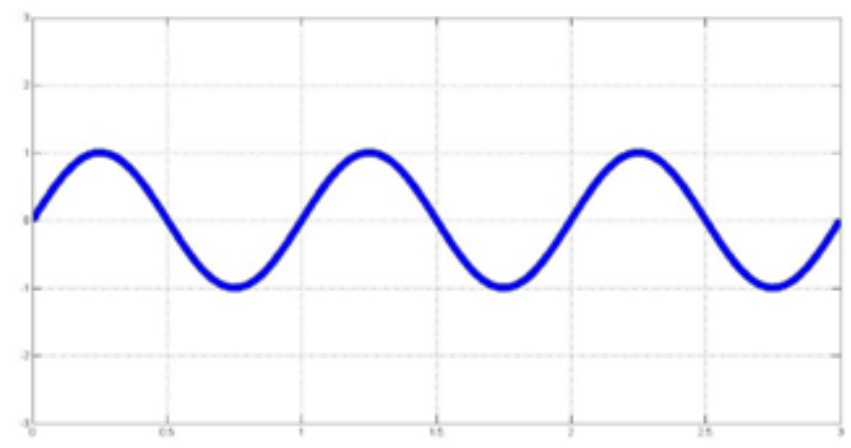

Figure 2. First sinusoid signal as $y_{1}=\sin (2 \pi t)$

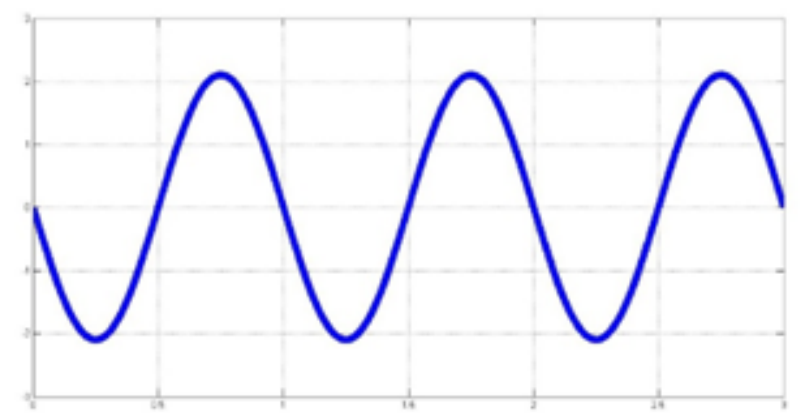

Figure 3. Second sinusoid signal is $\mathrm{y}_{2}=A \sin (2 \pi \mathrm{t})$ 


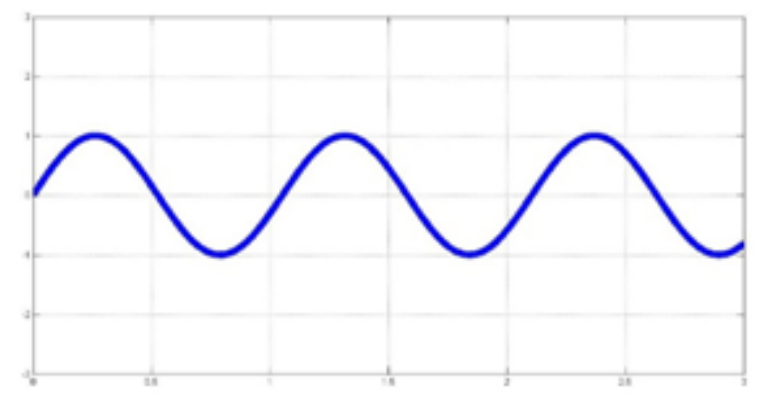

Figure 4. Third sinusoid signal is $\mathrm{y}_{3}=\sin (2 \pi \varpi \mathrm{t})$

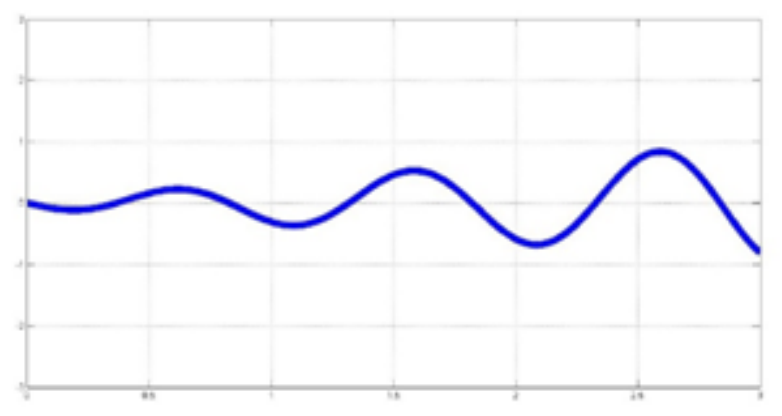

Figure 5. Summation of the three signals $\mathrm{y}_{4}=\mathrm{y}_{1}+\mathrm{y}_{2}+\mathrm{y}_{3}$

The video producer then combined all still image frames with corresponding formulae and text explanation to produce an instructional simulation using a professional animation tool, Motion. Considering the complexity of the content, we produced the simulation videos with special attention to related educational design principles.

- All videos are kept short, lasting between one to four minutes (Hibbert, 2014; Guo et al., 2014). Each video focuses on one concept and students view them in a sequential order, from the easiest to the more complicated.

- The information is presented to students in visual and text formats as well as in narration (Hibbert, 2014). All videos are fully accessible and students could turn on the caption if needed.

- The videos are directly embedded in pages in the LMS and students can easily view these videos on their computers and mobile devices. 
- The videos were produced professionally through animation. In the final video, students can view the actual transformation of the signal waveforms in a continuous fashion and also simultaneously connect the waveform transformation to corresponding mathematical formulas.

Six open-access videos were produced to illustrate signal waveform manipulation, understanding signal representation, mixing and decomposition. Students can gain insights on many topics; for example, how mathematics helps us to extract wanted signals from noise-corrupted received signals, and what causes fading in mobile communications. The following list includes the video links and brief descriptions of the topics:

- Video one: https://vimeo.com/cdlvideo/review/129452739/d9f6048784

The first video illustrates the mixture of two signals, i.e., the sum of two sine waveforms, in which we allow the second signal to change its phase from zero to 180 degrees.

- Video two: https://vimeo.com/cdlvideo/review/129451174/d036c0be74

The second video illustrates the mixture of two signals, in which the amplitude of the second signal changes from $-3 \mathrm{~V}$ to 0 and then back to $2 \mathrm{~V}$.

- Video three: https://vimeo.com/cdlvideo/review/129451170/09544bb960

The third video illustrates the mixture of two signals, in which the frequency of the second signal changes from $0.5 \mathrm{~Hz}$ to $2 \mathrm{~Hz}$.

- Video four: https://vimeo.com/cdlvideo/review/129451165/6a4750bcbb

In the fourth video, we see a mixture of three signals, in which the second signal changes in amplitude and the third one changes in frequency.

- Video five: https://vimeo.com/cdlvideo/review/129451164/78c65dda9a

The fifth video illustrates how to represent a signal (e.g., square waveform in $\left.y_{1}(t)\right)$ using another signal (e.g., a sinusoid waveform in $y_{2}(t)$ ).

- Video Six: $\underline{\text { https://vimeo.com/cdlvideo/review/129451161/a7959121bb }}$

In the sixth video, we repeat what appears in video 5 for several sinusoid waveforms, which leads to a representation of a signal (e.g., square waveform in $y_{1}(t)$ ) using Fourier series. 
These videos cannot only be accessed by enrolled students but are also an open-access resource on the video-streaming website, $\underline{\text { Vimeo. }}$

\section{Methods}

The video series were completed in October 2013. We began our research study in spring 2014. Given that there was relatively little educational research conducted at the post-secondary level or with a focus on electrical engineering (Streveler, et al., 2008) on fostering conceptual knowledge through simulations, we designed this research as an exploratory case study of students' experiences and perceptions. We used multiple sources of information for evaluating this instructional practice, including student survey, course evaluation, students' learning outcomes and interviews with the instructor and the teaching assistant. Our goal was to reflect on our instructional practice and improve the instructional videos for future semesters. The specific research questions were:

- How did students perceive the use of simulation videos for demonstrating key conceptual knowledge?

- What are the benefits and limitations of this instructional approach?

- What changes can we make to these videos to meet students' needs?

\subsection{Data collection}

At the beginning of the spring 2014 semester, the instructor introduced the videos to his students in class lectures. The videos were placed inside the LMS that was used to supplement the face-to-face lectures. Towards the end of the semester, we delivered an online survey facilitating students' feedback on the use of simulation videos in this course. Of the 67 students in the class, 62 volunteered to participate in this anonymous online survey. The response rate is $92.5 \%$. Students had the opportunity to offer further comments and suggestions at the end of the survey. In addition, the course evaluation ratings were reviewed, and the instructor and the teaching assistant were interviewed both at the beginning and at the end of the semester, using a semi-structured interview protocol that consisted of questions about the instructor perspectives. 


\subsection{Technology acceptance models}

In addition to usage and open-ended questions, the questionnaire (Table 1) consisted of 12 Likert-scale (1="Strongly Disagree"; 5="Strongly Agree") multiple-choice items derived from an existing Technology Acceptance Model (TAM) instrument (Chen, Sivo, Seilhamer, Sugar \& Jin, 2013) to measure students' perception of the usefulness, ease of use, attitude and intention to use the simulation videos. The reliability measures for the survey instrument were acceptable since the Cronbach's alpha of all variables are higher than 0.70 (The National Research Center for Distance Education and Technological Advancements, 2015).

\begin{tabular}{|cc|}
\hline Usefulness \\
\hline$\bullet$ & These videos were useful to help me understand the course content. \\
\hline • & These videos helped me in completing the course assignments. \\
\hline Ease of & These videos increased my general knowledge in engineering. \\
\hline - & These videos complemented face-to-face lectures. \\
\hline • & The videos are easy to understand. \\
\hline • & The video production is high in quality. \\
\hline Attitudes \\
\hline • & These videos made this course more interesting. \\
\hline • & The video length is appropriate. \\
\hline • & These videos encouraged me to think about the course content in a new way. \\
\hline Intention \\
\hline • & I would recommend these videos to my friends in the engineering program. \\
\hline • & I would like to see more videos like these in this class. \\
\hline • & I would like to see more videos in other engineering classes. \\
\hline
\end{tabular}

Table 1. Scales Used in the Survey Instrument

The Technology Acceptance Model (TAM) was first used to investigate innovation adoption in the fields of information systems and engineering in the past three decades (Davis, Bagozzi \& Warshaw, 1989; Davis, 1989; Venkatesh, Morris, Davis \& Davis, 2003). In the last decade, TAM has also been successfully used in the instructional technology field to explain students' behaviors in educational information systems (Chen et al., 2013; Rejón-Guardia, Sánchez-Fernández \& Muñoz-Leiva, 2013, Sivo \& Cheng-Chang, 2005; Sivo, Pan \& Hahs-Vaughn, 2007). The TAM framework focuses on the impact of user attitudes on behavioral outcomes and predicts the 
success of an information technology project. Therefore, we adapted this validated survey instrument to evaluate the use of simulation videos in teaching, with the objective to diagnose strengths and weaknesses of the media in the course of student learning and identify best practices to improve this instructional practice for future semesters. In particular, we included variables of usefulness, ease of use, attitudes, intention, and actual system use that are summarized below in Table 2 .

\begin{tabular}{|l|l|}
\hline Variables & Definition \\
\hline Ease of use & $\begin{array}{l}\text { The degree to which students believe that the use of simulation videos } \\
\text { is free of mental and physical efforts. }\end{array}$ \\
\hline Usefulness & $\begin{array}{l}\text { The degree to which students believe that the use of simulation videos } \\
\text { can enhance their study performance. }\end{array}$ \\
\hline Attitude & $\begin{array}{l}\text { The degree of positive or negative feelings towards using simulation } \\
\text { videos with his or her study. }\end{array}$ \\
\hline Intention & Strength of intention to use simulation videos for learning. \\
\hline Actual system use & $\begin{array}{l}\text { A behavioral response, measured by students' action, such as times they } \\
\text { watched the video. }\end{array}$ \\
\hline
\end{tabular}

Table 2. TAM Variables (Adapted from Chen et al., 2013)

\section{Results \& discussions}

To answer the three research questions, we analyzed both the quantitative survey results and the learning outcomes to evaluate students' perceptions towards the use of the media and potential learning benefits. In addition, we used the qualitative open-ended question and the instructor interviews to triangulate the quantitative results and further investigate if any changes need to be implemented to these videos to meet students' needs.

\subsection{Quantitative findings}

Overall, students rated all aspects of their video experience very high. All scales are higher than 4 out of the 5-point Likert Scale (Table 3).The respondents viewed all 6 videos; $66 \%$ watched them one time and $34 \%$ watched them two times or more (Figure 6 ). 


\begin{tabular}{|c|c|c|c|c|}
\hline Variables & Items & Mean & Std. Deviation & $\mathbf{N}$ \\
\hline \multirow{3}{*}{ Usefulness } & $\begin{array}{l}\text { These videos were useful to help me } \\
\text { understand the course content. }\end{array}$ & 4.31 & 0.50 & 62 \\
\hline & $\begin{array}{l}\text { These videos helped me in completing the } \\
\text { course assignments. }\end{array}$ & 4.05 & 0.78 & 62 \\
\hline & $\begin{array}{l}\text { These videos increased my general } \\
\text { knowledge in engineering. }\end{array}$ & 4.18 & 0.67 & 62 \\
\hline \multirow{3}{*}{ Ease of Use } & $\begin{array}{l}\text { These videos complemented face-to-face } \\
\text { lectures. }\end{array}$ & 4.34 & 0.75 & 62 \\
\hline & The videos are easy to understand. & 4.03 & 0.72 & 62 \\
\hline & The video production is high in quality. & 4.11 & 0.85 & 62 \\
\hline \multirow{3}{*}{ Attitude } & $\begin{array}{l}\text { These videos made this course more } \\
\text { interesting. }\end{array}$ & 3.82 & 0.84 & 62 \\
\hline & The video length is appropriate. & 4.29 & 0.66 & 62 \\
\hline & $\begin{array}{l}\text { These videos encouraged me to think } \\
\text { about the course content in a new way. }\end{array}$ & 3.89 & 0.87 & 62 \\
\hline \multirow{3}{*}{ Intention } & $\begin{array}{l}\text { I would recommend these videos to my } \\
\text { friends in the engineering program. }\end{array}$ & 4.16 & 0.79 & 62 \\
\hline & $\begin{array}{l}\text { I would like to see more videos like these } \\
\text { in this class. }\end{array}$ & 4.53 & 0.78 & 62 \\
\hline & $\begin{array}{l}\text { I would like to see more videos in other } \\
\text { engineering classes. }\end{array}$ & 4.21 & 0.89 & 62 \\
\hline
\end{tabular}

Table 3. Means and standard deviation of all questions with the four scales

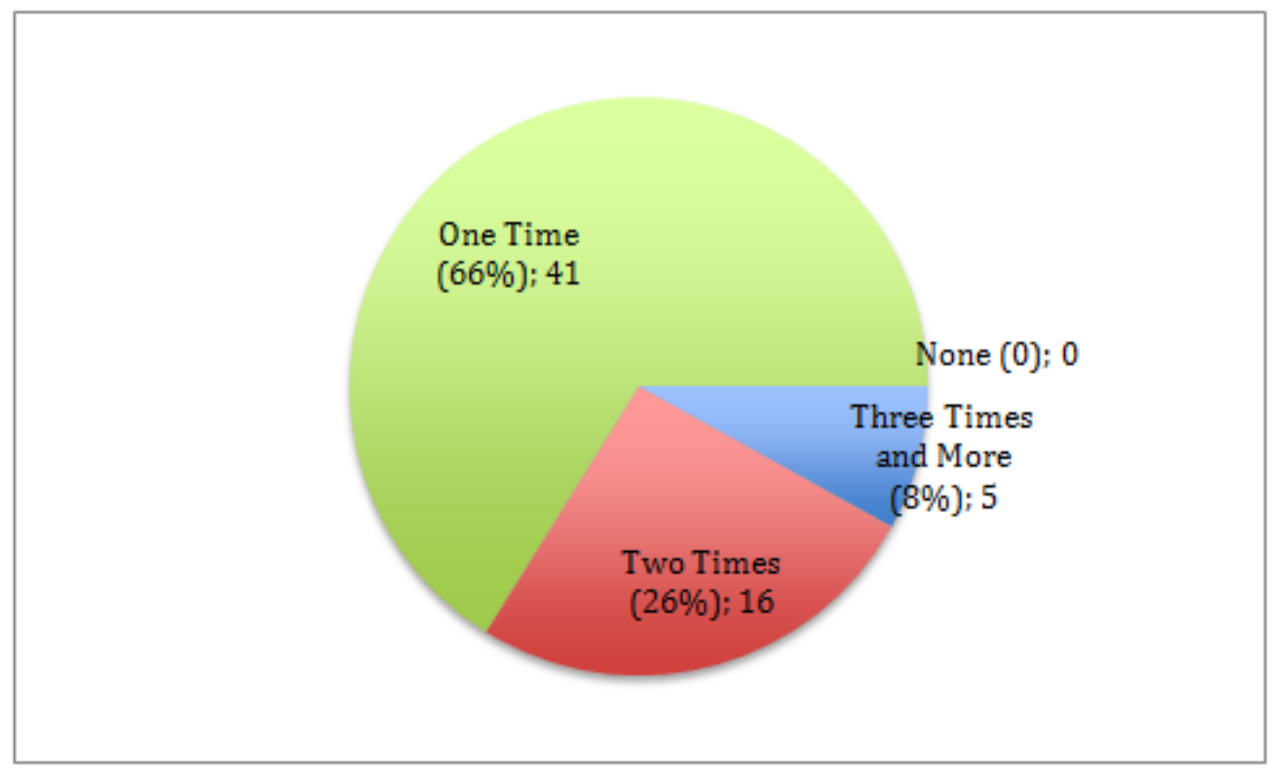

Figure 6. How many times students have watched the videos

We did not measure the direct learning outcomes of the videos in this case study. However, based on his interactions with the students, the instructor reported that students had a better understanding of the fundamental concepts that helped them in subsequent assignments and tests. Therefore, we compared the final scores between the 2014 spring semester and the 
previous semester (2013 fall semester with no video intervention) and found a statistically significant increase. The 2014 cohort $(M=86.12, S D=8.15)$ performed statistically significantly $(t(118)=-3.045, p=0.003)$ better than the previous cohort $(M=81.60, S D=7.96)$. This could indicate a learning benefit of those videos. However, without controlled experimental studies, such an assumption cannot be confirmed.

\subsection{Qualitative findings}

In addition, the open-ended answers from the survey and the instructor/TA interviews were reviewed and coded. Major themes were noted and discussed in conjunction with details of the survey ratings as follows.

\subsubsection{Theme: Usefulness}

The survey results indicated that students agreed that the videos were useful for learning. They perceived that the videos complemented the face-to-face lectures (mean=4.34 out of 5), and helped them understand the course content (mean=4.31 out of 5). Students commented that they viewed the videos when they did not understand the course subject after attending the faceto-face lectures and reading the provided slides. For instance, one student commented, "The videos are helpful and allow me to listen to the material again if I don't understand the first time." Another said, "I found myself re-watching to catch important information which I missed." They found the best time to view these videos was right after each lecture and they liked that they could pause and re-play the videos. The students also liked that these simulations leverage several modes of information representation, such as illustrated texts, audio and videos. For example, one student said, "It's amazing how understanding increases with the right visual." And another one found that "the subtitles (captions) were helpful." The same trend emerged from the course evaluation feedback: the students found the online videos to be helpful.

The instructor interviews corroborate students' survey responses. At the beginning of the semester, the instructor had high expectations of these simulation videos. The instructor commented that students entering into foundational communications courses had never encountered challenging concepts like these in their daily life. It is not surprising that a large number of students struggled in the first half of the semester. As the semester progressed, they gradually learned to handle these challenges. He found that these videos helped students 
overcome the challenges faster and smooth out the steep learning curve. At the end of the semester, the instructor reported that students performed better in quizzes and tests. The final scores seem to suggest a potential positive impact of the simulation videos on students' learning outcomes. However, causal effects on learning outcomes are beyond the scope of this case study. This would be interesting follow-up research for the future.

\subsubsection{Theme: Length of videos}

Students found that the videos are easy to understand and they had no technical issues playing the videos. They rated the quality of the video as high (mean=4.11 out of 5 ) and the length of the video as appropriate (mean=4.29 out of 5). The length of the first four videos is a little bit over one minute. The last two videos illustrate more complicated concepts and last between twoand four-minutes long. A few students suggested that the videos could be longer. One student commented, "The videos helped me to get a better understanding of signals. I think the signal mixtures of two signals that result in a third could be explained a bit more in details. I had to rewind the videos couple of times to see what exactly was happening. Thank you for these videos."

These valuable feedbacks help us make more engaging videos for the future. Research indicates that the optimal video length is six minutes or shorter and students' engagement times decrease as videos lengthen afterwards (Hibbert, 2014; Guo et al., 2014). In particular, short videos (0-3 minutes) had the highest student engagement (Guo et al., 2014). Therefore, we will continue to produce short and focused videos on other topics. Since the real-time simulation happens very fast in the first four videos, one revision is to record the core steps of the operation (mixing, decomposition, etc.) in slow motion before the real-time simulation. Or we can expand the oneminute videos by repeating the whole animation in slow motion so students do not need to pause and rewind to see the transformation process. 


\subsubsection{Theme: Assessment}

Even though students agreed that the videos could help them in understanding the course contents (mean=4.31 out of 5) and increase their general knowledge of electrical engineering (mean $=4.18$ out of 5 ), some students failed to see a connection between these videos on basic concepts and their course assignments (mean=4.05 out of 5). One student suggested, "I thought the videos were a great addition to the class. However, I did feel as though the homework assignments were always unclear of how to start them or how to do the problems. The lectures and videos seemed a little disconnected from the homework problems. Maybe include more example problems so students can refer to those when working on the assignments."

Both the instructor and the teaching assistant agreed that some students did not see the importance of the fundamental concepts that are illustrated in the videos. However, if student do not understand these concepts, they will not be able to complete the course assignments successfully. Furthermore, it takes time for students to establish concepts as they work through the problems over the semester. The instructor found it typical for students to take 8 to 10 weeks of a 15-week semester to establish concepts and make connections. Therefore, students have struggled in the first 10 weeks. As a result, the instructor proposed to create post-video assessments such as multiple-choice question problems for future semesters. Hopefully, the assessments will help students quickly establish concepts and connect the illustrated concepts with their final course assignments (Hibbert, 2014).

\subsubsection{Theme: Intention}

An overwhelming theme is that students wanted more videos as learning resources. The intention was rated as the highest among all measures. Students indicated that they would like to see more videos in this course (mean $=4.21$ out of 5 ) and, more importantly, in other electrical engineering courses (mean=4.53 out of 5). One student commented, "I actually liked the videos and would have liked to see videos of signals accompany the lectures throughout the semester. Seeing videos such as how something looks when it modulates, demodulates before you get to ...lab... seems like it may help when it comes to viewing the signals and confirming that lab results achieved the signal." Another comment is, "I can see these videos being very helpful in visualizing some more difficult concepts in the course where simply reading text does not help students grasp the concepts being introduced." 
In addition, students stated that they had rarely received resources like this in their previous engineering courses. One student said, "The videos are very helpful and I wish more classes offered resources like that." Another one expressed the same interest, "I hope that other professors begin to utilize videos to help compliment the learning process." These are not isolate comments. More than half of the respondents expressed interests in viewing more videos in the open-ended question. Students also commented that they would highly recommend this course to their friends (mean=4.16 out of 5) and would like to download these videos for future references.

\section{Conclusions \& future directions}

Our findings indicate that students find the simulation videos very useful in understanding complicated engineering concepts. These simulations promote situated understanding through short and memorable multimedia video clips, leveraging several modes of representation information such as illustrated texts, audio and videos to meet students' learning needs and reinforce difficult concepts and problem-solving processes. Based on students comments, we would like to modify some videos so complicated transformations can be viewed in slow motion and post-video assessments will be designed to complement the resources. The following are some of the educational design considerations for producing an instructional video drawn from this study:

- High-quality videos with professionally-produced simulations are engaging.

- Chunk the content into small videos (1-4 minutes) and recommend students watch in a sequential order from the easiest concepts to the more complicated.

- Present the information in visual and text formats as well as in narration. Caption the videos.

- Stream the videos so students can easily access them with all devices. And allow them to view the content in slow or fast motion.

- Create post-video assessments and help students connect the video content with major course assignments. 
With the above design considerations in mind, we aim to continue producing more simulation videos. In addition to these six videos, the design team will work on a second series of videos on the concept of signal time domain operations and a will produce a third series of videos on eyediagram in the near future. After the pilot, all videos will be used in EEL3552C and two other classes, EEL 4515 (Digital Communication Systems) and EEL 6530 (Communication theory). Since all videos are openly-accessible on the public Vimeo site, we would like to invite engineering instructors outside of UCF to use them for teaching. We believe that students from other classes such as Signal and System or Digital Signal Processing could benefit from watching these simulation videos as well.

We plan to evaluate the impact of these simulation videos systematically. A possible future direction is to examine if these simulation videos will impact students learning outcomes via experimental research. We hope that the findings from our case study can help inform electrical engineering instructors to transform their teaching practice and eventually benefit students through building a solid conceptual understanding that fosters the development of further engineering competencies.

\section{References}

Chen, B., Sivo, S., Seilhamer, R., Sugar, A., \& Jin, M. (2013, September). User acceptance of mobile technology: A campus-wide implementation of Blackboard's Mobile TM Learn application. Journal of Educational Computer Research, 49(3), 327-343. http://dx.doi.org/10.2190/EC.49.3.c

Chi, M.T.H. (2005). Commonsense conceptions of emergent processes: Why some misconceptions are robust. Journal of Learning Sciences, 14(2), 161-199. http://dx.doi.org/10.1207/s15327809j1s1402_1

Davis, F.D. (1989). Perceived usefulness, perceived ease of use, and user acceptance of information technology. MIS quarterly, 13(3), 319-340. http://dx.doi.org/10.2307/249008

Davis, F.D., Bagozzi, R.P., \& Warshaw, P.R. (1989). User acceptance of computer technology: A comparison of two theoretical models. Management Science, 982-1003. 
Guo, P.J., Kim, J., \& Rubin, R. (2014). How video production affects student engagement: An empirical study of MOOC videos. Proceedings from the First ACM Conference on Learning @ Scale Conference. New York, NY. 41-50. http://dx.doi.org/10.1145/2556325.2566239

Hibbert, M. (2014). What makes an instructional video compelling?. EDUCAUSE Review Online. Retrieved from: http://er.educause.edu/articles/2014/4/what-makes-an-online-instructional-video-compelling

Kapli, N.V. (2010). The effects of segmented multimedia worked examples and self-explanations on acquisition of conceptual knowledge and problem-solving performance in an undergraduate engineering course (Doctoral dissertation). Retrieved from ProQuest LLC.

Lauterbach, M. (1997). Getting more out of eye diagrams. IEEE Spectrum, 34(3), 60-63. http://dx.doi.org/10.1109/6.576010

Marques, J.C., Quintela, J., Restivo, M.T., \& Trigo, V.M. (2013, February). Engineering, concepts and video clips. International Journal of Engineering Pedagogy, 3, 22.

Mayer, R. (2002, Spring). Cognitive theory and the design of multimedia instruction: An example of the two-way street between cognition and instruction. New directions for teaching and learning, 2002 (89), 55-71. http://dx.doi.org/10.1002/tl.47

Rejón-Guardia, F., Sánchez-Fernández, J., \& Muñoz-Leiva, F. (2013). The acceptance of microblogging in the learning process: The $\mu \mathrm{BAM}$ model. Journal of Technology and Science Education, 3(1), 31-48. http://dx.doi.org/10.3926/jotse.65

Sivo, S.A., \& Cheng-Chang, P. (2005). Undergraduate Engineering and Psychology Students' Use of a Course Management System: A Factorial Invariance Study of User Characteristics and Attitudes. Journal of Technology Studies, 31(2), 94-103. http://dx.doi.org/10.21061/jots.v31i2.a.4

Sivo, S.A., Pan, C.-C., \& Hahs-Vaughn, D.L. (2007). Combined Longitudinal Effects of Attitude and Subjective Norms on Student Outcomes in a Web-Enhanced Course: A Structural Equation Modelling Approach. British Journal of Educational Technology, 38(5), 861-875. http://dx.doi.org/10.1111/j.1467-8535.2006.00672.x

Streveler, R.A., Litzinger, T.A., Miller, R.L., \& Steif, P.S. (2008). Learning conceptual knowledge in the engineering sciences: Overview and future research directions. Journal of Engineering Education, 97(3), 279-294. http://dx.doi.org/10.1002/j.2168-9830.2008.tb00979.x 
The National Research Center for Distance Education and Technological Advancements (DETA). (2015). DETA research toolkit. University $f$ Wisconsin-Milwankee. Retrieved from: http://uwm.edu/deta/toolkits/

Venkatesh, V., Morris, M.G., Davis, G.B., \& Davis, F.D. (2003). User acceptance of information technology: Toward a unified view. MIS Quarterly, 27(3), 425-478.

Published by OmniaScience (www.omniascience.com)

Journal of Technology and Science Education, 2016 (www.jotse.org)

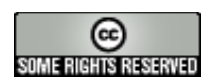

Article's contents are provided on an Attribution-Non Commercial 3.0 Creative commons license. Readers are allowed to copy, distribute and communicate article's contents, provided the author's and JOTSE journal's names are included. It must not be used for commercial purposes. To see the complete licence contents, please visit http://creativecommons.org/licenses/by-nc/3.0/es/ 